\title{
The genomic underpinnings of apoptosis in the silkworm, Bombyx mori
}

\author{
Jin-Ye Zhang ${ }^{\dagger}$, Min-Hui Pan ${ }^{\dagger}$, Zhi-Ya Sun, Shu-Jing Huang, Zi-Shu Yu, Di Liu, Dan-Hong Zhao, Cheng Lu*
}

\begin{abstract}
Background: Apoptosis is regulated in an orderly fashion by a series of genes, and has a crucial role in important physiological processes such as growth development, immunological response and so on. Recently, substantial studies have been undertaken on apoptosis in model animals including humans, fruit flies, and the nematode. However, the lack of genomic data for silkworms limits their usefulness in apoptosis studies, despite the advantages of silkworm as a representative of Lepidoptera and an effective model system. Herein we have identified apoptosis-related genes in the silkworm Bombyx mori and compared them to those from insects, mammals, and nematodes.

Results: From the newly assembled genome databases, a genome-wide analysis of apoptosis-related genes in Bombyx mori was performed using both nucleotide and protein Blast searches. Fifty-two apoptosis-related candidate genes were identified, including five caspase family members, two tumor necrosis factor (TNF) superfamily members, one BCl-2 family member, four baculovirus IAP (inhibitor of apoptosis) repeat (BIR) domain family members and 1 RHG (Reaper, Hid, Grim, and Sickle; Drosophila cell death activators) family member. Moreover, we identified a new caspase family member, BmCaspase-New, two splice variants of BmDronc, and Bm3585, a mammalian TNF superfamily member homolog. Twenty-three of these apoptosis-related genes were cloned and sequenced using CDNA templates isolated from BmE-SWU1 cells. Sequence analyses revealed that these genes could have key roles in apoptosis.

Conclusions: Bombyx mori possesses potential apoptosis-related genes. We hypothesized that the classic intrinsic and extrinsic apoptotic pathways potentially are active in Bombyx mori. These results lay the foundation for further apoptosis-related study in Bombyx mori.
\end{abstract}

\section{Background}

Programmed cell death [1], as well as cell proliferation and cell differentiation, has a crucial role in biological growth and development. There are two primary programmed cell death signaling pathways [2], apoptosis [3] and autophagy [4], of which apoptosis has been researched more extensively. Apoptosis is characterized by morphological changes and biochemical events such as cytoplasmic and nuclear condensation, phosphatidylserine extrusion, vacuolization, chromatin condensation, DNA fragmentation, and formation of apoptotic bodies that are ultimately engulfed by surrounding cells or

\footnotetext{
* Correspondence: lucheng@swu.edu.cn

+ Contributed equally

The Key Sericultural Laboratory of Agricultural Ministry, Institute of

Sericulture and Systems Biology, Southwest University, Chongqing 400715,
} China

(c) 2010 Zhang et al; licensee BioMed Central Ltd. This is an Open Access article distributed under the terms of the Creative Commons Attribution License (http://creativecommons.org/licenses/by/2.0), which permits unrestricted use, distribution, and reproduction in any medium, provided the original work is properly cited. macrophages [2]. Cell death by autophagy involves cell degradation by internal lysozymes [4]. There are very important connections between apoptotic cell death and autophagic cell death, as they occur concurrently in many processes [5].

Apoptotic mechanisms are being clarified in model organisms using completed genome sequences, especially in nematodes, fruit flies and humans. Compared to Drosophila and humans, the apoptosis network in nematodes is much simpler [6]. There are several differences in apoptotic mechanisms between mammals and nematodes. In mammals, two primary apoptotic signaling pathways have been described: the extrinsic pathway, which is initiated by the tumor necrosis factor (TNF)/ nerve growth factor (NGF) receptors superfamily [7-11], and the intrinsic pathway, which include the mitochondrial pathway, the endoplasmic reticulum pathway and 
the DNA damage pathway [12-15]. The intrinsic and extrinsic pathways are connected by caspase-mediated activation of the pro-apoptotic Bcl-2 family member BID and the c-Jun N-terminal kinases (JNK), which converge on effector caspase activation [16-19]. Most insect apoptosis research has used Drosophila. There are some fundamental differences in apoptotic signaling pathways between Drosophila and mammals. For example, the absence of RHG (Reaper, Hid, Grim and Sickle) family proteins virtually blocks apoptosis [20]. Although Smac/ Dablo and Htra2/Omi are functional homologs of the RHG family, their apoptotic roles are not as critical in vertebrates as RHG is in Drosophila [21]. Furthermore, cytochrome-c is dispensable for caspase activation [22-26] and it is unclear whether mitochondria participate in apoptosis $[27,28]$ in Drosophila. Kumarswamya and colleagues [29] recently used Sf9 cells to demonstrate that cyosolic cytochrome-c release is an essential event for caspase activation during Lepidopteran apoptosis, and that cytochrome-c release might occur independent of mitochondrial membrane potential loss and permeability transition pore formation. Furthermore, cytochrome-c has been detected by Western blot in the cytoplasm of UV-induced apoptotic silkworm cells, BmE-SWU1 [30]. These all are distinctively different from the mechanisms reported in Drosophila, but are similar to mammalian apoptosis.

The domestic silkworm Bombyx mori (a representative of Lepidoptera) has important economic value. Investigation into apoptosis in Lepidotera began at the same time as Drosophila [31,32]. Since intersegmental muscle apoptosis was studied in 1965 [31], apoptosis research in silkworm has lagged far behind that of other organisms until the 1990s. Now, apoptosis research in silkworms mainly focus on two aspects. First, the morphological changes in tissues and cells during apoptosis-induced by extrinsic factors (such as ecdysone [33] or hemolymph [34-41]) and intrinsic factors (such as actinomycin D, ultraviolet light, and viruses [42-46]), the individual organs (e.g. wing or palea) in Bombyx mori apoptotic mutants [47] and tissues (midgut, silk gland) during metamorphosis [48]. The second aspect is gene cloning and identification. Tambunan [49] found that BmP109 in Bombyx mori contains the four conserved Bcl-2 homology $(\mathrm{BH})$ regions, $\mathrm{BH} 1, \mathrm{BH} 2, \mathrm{BH} 3$, and $\mathrm{BH} 4$. Huang and colleagues [50] have cloned the IAP (inhibitor of apoptosis) homolog BmIAP from Bombyx mori BmN cells, and found that BmIAP inhibits apoptosis induced by Bax, but not Fas, in mammalian cells. Their biochemical data also suggested that BmIAP is a specific inhibitor of mammalian Caspase-9, but not the downstream effectors caspase- 3 and caspase-7. In the same year, Kim and colleagues [34] reported that the $30 \mathrm{~K}$ protein from silkworm hemolymph inhibits virus- or chemical-induced apoptosis in human cells as well as insect cells, although the mechanism remains unknown. The first caspase family member identified was BmCaspase-1 in BmN cells [51]. Subsequently, the caspase family members $B m I C E$ [52], BmICE-2 and BmICE-5 [53] were cloned from Bombyx mori midgut and BmE cells. Recently, Bryant and colleagues [54] demonstrated both Drosophila DmReaper and its Bombyx mori ortholog BmReaper possessed conservative IAP binding and GH3 (Grim Helix 3) motifs. The Bombyx mori homologs BmPkc [55], BmIcad [56], and $B m C d c 2$ [57] also have been cloned. However, how these genes participate in apoptosis in the silkworm is still unclear, and this area of research has been very fragmented.

Apoptotic mechanisms in model organisms (such as the nematode, Drosophila and mammals) can not accurately reflect the apoptotic mechanisms in silkworm. For these reasons, comprehensive and in-depth apoptosis research in Bombyx mori is urgent. Fortunately, the completion of the silkworm genome sequence [58] and a whole-genome chip [59] provide important tools for apoptosis research in Bombyx mori. Herein we looked for possible apoptosis-related homologs using information analysis in $9 \times$ genome sequencing data. Genes of interest were cloned and verified using cDNA templates isolated from the BmE cell line and different developmental stages of Bombyx mori. Finally, the potential apoptotic pathways in which these genes may act in Bombyx mori were analyzed.

\section{Results}

\section{Identification of silkworm apoptosis-related genes}

We have identified 52 apoptosis-related genes, including five members of the caspase family ( $B m I C E, B m I C E-2$ and $B m I C E-5$ are splice variants of BmICE; BmDroncL and BmDroncS are splice variants of BmDronc). We have also identified one member of the Bcl-2 family, two members of the TNF superfamily (TNFSF), and four members of the baculovirus IAP repeat (BIR) domain family in Bombyx mori (Table 1). Seventeen genes (BmAkt, BmCaspase-1, BmICE, BmDredd, BmCdc2, BmCyt C, BmErk, BmICAD, BmIAP, BmICE-2, BmICE-5, BmJnk, BmPdk, BmPka,BmPkc, BmRas, BmReaper, $B m S i r 2$, and BmStat) have been previously included in $\mathrm{NCBI}$, among which ten genes have been reported in Bombyx mori including BmCaspase-1 [51], BmICE [52], $B m C d c 2$ [57], BmErk [60], BmICAD [56], BmIAP [50], BmJnk [61], BmPkc [55], BmReaper [56], BmCyt C [30], BmICE-2 and BmICE-5 [53] (Additional file 1 Table A). Thirty five apoptosis genes were identified (Table 1) and accepted by the NCBI (Gene IDs are provided in detail in Additional file 1 Table B). These silkworm apoptosis-related genes are located on most of the 28 chromosomes, except the chromosomes 1, 6, 19, 24, 


\begin{tabular}{|c|c|c|c|c|c|c|c|c|c|c|}
\hline \multirow{2}{*}{$\begin{array}{l}\text { Gene } \\
\text { name }\end{array}$} & \multirow[t]{2}{*}{ Gene holoname } & \multirow{2}{*}{$\begin{array}{l}\text { ORF } \\
\text { length } \\
\text { (bp) }\end{array}$} & \multirow{2}{*}{$\begin{array}{l}\text { Extron } \\
\text { number }\end{array}$} & \multirow{2}{*}{$\begin{array}{l}\text { Chromosome } \\
\text { No. }\end{array}$} & \multirow[t]{2}{*}{ Scoffold } & \multirow[t]{2}{*}{ Domain } & \multicolumn{2}{|c|}{ Est } & \multirow[t]{2}{*}{ Prober No. } & \multirow{2}{*}{$\begin{array}{l}\text { Ncbi } \\
\text { E-value }\end{array}$} \\
\hline & & & & & & & number & integrity & & \\
\hline BmAcinus & $\begin{array}{l}\text { apoptotic chromatin condensation } \\
\text { inducer in the nucleus }\end{array}$ & 2442 & 4 & 4 & nscaf2847 & No domain & 4 & 0 & sw01266 & $2 e-113$ \\
\hline BmAif & apoptosis-inducing factor & 1794 & 13 & 14 & scaffold416 & Pyr_redox superfamily domain & 2 & 0 & sw03811 & $3 e-86$ \\
\hline BmAkt & pbk & 1410 & 8 & 18 & nscaf2902 & $\begin{array}{l}\text { PH-like superfamily/PKc-like } \\
\text { superfamily domain }\end{array}$ & 2 & 0 & $\begin{array}{l}\text { sw17926 } \\
\text { sw07695 }\end{array}$ & 0.0 \\
\hline BmApaf-1 & $\begin{array}{l}\text { apoptotic peptidase activating } \\
\text { factor } 1\end{array}$ & 4302 & 18 & 23 & nscaf3015 & CARD/WD40 superfamily domain & 1 & 0 & sw17785 & $4 e-41$ \\
\hline BmApp & amyloid precursor protein & 2067 & 15 & 18 & nscaf2902 & $\begin{array}{l}\text { A4_Extra superfamily/GBP_C } \\
\text { domain }\end{array}$ & 0 & 0 & sw03656 & 0.0 \\
\hline BmAsk1 & apoptosis signal-regulating kinase 1 & 4041 & 24 & 12 & nscaf2993 & S_TKc/SAM domain & 0 & 0 & sw19703 & 0.0 \\
\hline BmAtf2 & activating transcription factor 2 & 1134 & 4 & 2 & nscaf2053 & ZnF_C2H2 domain & 0 & 0 & sw15358 & $4 e-24$ \\
\hline BmBuffy & B-cell lymphoma protein 2 & 879 & 6 & 4,7 & $\begin{array}{l}\text { nscaf2981 } \\
\text { nscaf2983 } \\
\text { nscaf3077 }\end{array}$ & Bcl2family domain & 3 & 0 & sw21409 & $5 e-23$ \\
\hline $\begin{array}{l}\text { BmCaspase- } \\
1\end{array}$ & $\begin{array}{l}\text { cysteine aspartic acic specific } \\
\text { protease } 1\end{array}$ & 882 & 1 & 10 & nscaf2860 & CASc domain & 8 & 1 & sw04417 & 0.0 \\
\hline$B m / C E-5$ & $\begin{array}{l}\text { cysteine aspartic acic specific } \\
\text { protease } 3 \mathrm{~L}\end{array}$ & 939 & 9 & 4 & nscaf2847 & CASc domain & 10 & 1 & sw22502 & 0.0 \\
\hline$B m / C E-2$ & $\begin{array}{l}\text { cysteine aspartic acic specific } \\
\text { protease } 3 S\end{array}$ & 855 & 8 & 4 & nscaf2847 & CASc domain & 10 & 1 & sw22502 & $1 e-65$ \\
\hline$B M / C E$ & interleukin converting enzyme & 828 & 7 & 4 & nscaf2847 & CASc domain & 10 & 1 & sw22502 & 0.0 \\
\hline BmDredd & $\begin{array}{l}\text { cysteine aspartic acic specific } \\
\text { protease } 8\end{array}$ & 1632 & 1 & 10 & nscaf2855 & CASc domain & 1 & 0 & Not found & 0.0 \\
\hline BmDroncL & $\begin{array}{l}\text { cysteine aspartic acic specific } \\
\text { protease } 9 \mathrm{~L}\end{array}$ & 1233 & 7 & 10 & nscaf2575 & CARD/CASc domain & 1 & 0 & sw12316 & $2 e-41$ \\
\hline BmDroncs & $\begin{array}{l}\text { cysteine aspartic acic specific } \\
\text { protease } 95\end{array}$ & 552 & 5 & 10 & nscaf2575 & CARD/CASc domain & 1 & 0 & sw12316 & $1 e-15$ \\
\hline $\begin{array}{l}\text { BmCaspase- } \\
N\end{array}$ & $\begin{array}{l}\text { cysteine aspartic acic specific } \\
\text { protease New }\end{array}$ & 1071 & 4 & 20 & nscaf2795 & CASc domain & 2 & 0 & sw04445 & $1 e-28$ \\
\hline$B m C d c 2$ & cell division cycle2 & 960 & 7 & 16 & nscaf3062 & Protein_kinase_domain & 1 & 1 & sw02944 & 0.0 \\
\hline BmCreb & $\begin{array}{l}\text { CAMP response element binding } \\
\text { protein }\end{array}$ & 894 & 6 & 10 & nscaf2859 & $\begin{array}{l}\text { pKID superfamily/bZIP_1 } \\
\text { superfamily domain }\end{array}$ & 4 & 1 & sw14332 & $1 e-145$ \\
\hline BmCyt c & cytochrome c & 327 & 3 & 3 & nscaf2930 & Cytochrom_C superfamily domain & 45 & 1 & sw15825 & $9 e-58$ \\
\hline BmDapk & death-associated protein kinase 1 & 1242 & 7 & 10 & nscaf2855 & PKc_like superfamily/S_TKc domain & 0 & 0 & sw11691 & $2 e-68$ \\
\hline BmDaxx & $\begin{array}{l}\text { Fas death-domain associated } \\
\text { protein }\end{array}$ & 1785 & 6 & 3 & nscaf2886 & Daxx superfamily & 3 & 0 & sw18609 & $2 e-12$ \\
\hline BmEndoG & endonuclease G & 807 & 6 & 20 & nscaf2789 & NUC superfamily domain & 0 & 0 & sw12629 & $2 \mathrm{e}-117$ \\
\hline BmErk & extracellular-signal regulating kinase & 990 & 7 & 10 & nscaf2855 & PKc_like superfamily & 0 & 0 & sw13977 & 0.0 \\
\hline BmFadd & fas-associated via death domain & 666 & 2 & 22 & nscaf1681 & Death superfamily domain & 1 & 0 & Not found & 0.89 \\
\hline BmFkhr & $\begin{array}{l}\text { forkhead homolog in } \\
\text { rhabdomyosarcoma }\end{array}$ & 480 & 3 & 9 & nscaf2890 & FH superfamily domain & 1 & 0 & $\begin{array}{l}\text { sw09818 } \\
\text { sw11611 }\end{array}$ & $2 e-44$ \\
\hline
\end{tabular}


Table 1 Apoptosis-related genes of Bombyx mori (Continued)

\begin{tabular}{|c|c|c|c|c|c|c|c|c|c|c|}
\hline BmGas2 & growth arrest specific 2 & 1938 & 9 & 14 & nscaf2948 & $\mathrm{CH}$ superfamily/gas2 superfamily & 5 & 0 & $\begin{array}{l}\text { sw12456 } \\
\text { sw00851 } \\
\text { sw05095 }\end{array}$ & $6 e-106$ \\
\hline BmGsk3 & glycogen Synthase Kinase-3 & 945 & 7 & 18 & nscaf2902 & $\begin{array}{l}\text { S_TKc/PKc_like superfamily/Pkinase } \\
\text { domain }\end{array}$ & 4 & 0 & Not found & 2e-159 \\
\hline BmHtra2 & High temperature requirement $\mathrm{A} 2$ & 1740 & 11 & 26 & nscaf 2330 & $\begin{array}{l}\text { ROK/TrypP_SPc/PDZ superfamily } \\
\text { domain }\end{array}$ & 4 & 0 & sw00567 & $1 e-113$ \\
\hline Bmlcad & $\begin{array}{l}\text { inhibitor of caspase-activated } \\
\text { DNase }\end{array}$ & 594 & 2 & 23 & nscaf3015 & CIDE-N superfamily domain & 3 & 0 & sw01954 & 0.0 \\
\hline Bmlap & inhibitor of apoptosis protein & 1041 & 2 & 23 & nscaf3027 & BIR superfamily domain & 34 & 1 & sw22890 & 0.0 \\
\hline Bmlap2 & inhibitor of apoptosis 2 protein & 1686 & 9 & 23 & nscaf3027 & BIR superfamily domain & 2 & 0 & $\begin{array}{l}\text { sw14099 } \\
\text { sw01498 }\end{array}$ & $8 e-97$ \\
\hline BmBruce & - & 12711 & 59 & 25 & nscaf2823 & BIR superfamily domain & 5 & 0 & sw10962 & 0.0 \\
\hline BmSurvivin & - - & 411 & 3 & 17 & nscaf2766 & BIR superfamily domain & 16 & 0 & sw16094 & $5 e-32$ \\
\hline BmJnk & c-Jun N-terminal kinase & 1146 & 9 & 3 & nscaf2883 & PKc_like superfamily domain & 2 & 0 & sw14613 & 0.0 \\
\hline Bmmkk7 & $\begin{array}{l}\text { mitogen-activate protein kinase } \\
\text { kinase } 7\end{array}$ & 1230 & 10 & 15 & nscaf2888 & PKc_like superfamily domain & 0 & 0 & sw18329 & $4 e-138$ \\
\hline BmP53 & - & 546 & 3 & 16 & nscaf3063 & P53-superfamily & 1 & 0 & sw20071 & $9 e-14$ \\
\hline BmP70s6k & p70 ribosomal protein 56 kinase & 936 & 6 & 10 & nscaf2859 & PKc_like superfamily & 2 & 0 & sw00674 & $4 \mathrm{e}-90$ \\
\hline BmP90srk & p90 ribosomal S6 kinase & 2262 & 13 & 23 & nscaf3015 & S_TKc/PKc_like superfamily & 0 & 0 & sw22237 & 0.0 \\
\hline BmPax6 & paired box gene 6 & 552 & 3 & 14 & nscaf2953 & pax superfamily & 1 & 0 & sw01861 & $2 e-69$ \\
\hline BmParp & poly ADP ribose polymerase & 2898 & 18 & 22 & nscaf2813 & $\begin{array}{l}\text { WGR/ADP ribosyl superfamily } \\
\text { domain }\end{array}$ & 6 & 0 & sw03907 & 0.0 \\
\hline Bmpdk & pyruvate dehydrogenase kinase & 1299 & 9 & 2 & nscaf2623 & HATPase_c superfamily domain & 4 & 0 & sw15422 & 0.0 \\
\hline BmPi3k & phosphatidylinositol 3-kinase & 1197 & 4 & 12 & nscaf2993 & SH2 superfamily domain & 1 & 0 & sw21185 & 0.0 \\
\hline BmPka & protein kinase $\mathrm{A}$ & 1062 & 1 & 23 & nscaf3027 & PKc_like superfamily & 0 & 0 & sw08116 & 0.0 \\
\hline$B m P k c$ & protein kinase $\mathrm{C}$ & 1590 & 8 & 8 & nscaf463 & C2/PKc_like superfamily & 0 & 0 & sw05322 & 0.0 \\
\hline BmRaf & - & 2103 & 11 & 15 & nscaf2888 & VBQ/PKc_like superfamily & 0 & 0 & sw17787 & 0.0 \\
\hline BmRas & renin-angiotensin system & 579 & 2 & 21 & nscaf2868 & $\begin{array}{l}\text { P_loop_NTPase superfamily } \\
\text { domain }\end{array}$ & 1 & 1 & sw09841 & 0.0 \\
\hline BmReaper & - - & 93 & 1 & 7 & nscaf2983 & IBM binding and GH3 motifs & 2 & 1 & Not found & \\
\hline BmRock1 & Rho kinase & 4083 & 12 & 4 & nscaf2589 & PKc_like superfamily & 0 & 0 & sw12299 & 0.0 \\
\hline BmSir2 & silent information regulator 2 & 1872 & 11 & 25 & nscaf2823 & ASC/SIR2 superfamily & 2 & 0 & sw10596 & 0.0 \\
\hline BmStat & $\begin{array}{l}\text { signal transducer and activator of } \\
\text { transcription }\end{array}$ & 2178 & 21 & 11 & nscaf2176 & $\begin{array}{l}\text { STAT_int/STAT_alpha/STAT_bind/ } \\
\text { SH2 superfamily domain }\end{array}$ & 4 & 0 & sw09865 & 0.0 \\
\hline BmTak1 & TGF-beta-activated kinase 1 & 1197 & 7 & 26 & nscaf3003 & PP2Cc superfamily domain & 2 & 0 & sw14675 & $7 e-87$ \\
\hline BmTNFSF5 & $\begin{array}{l}\text { Tumor Necrosis Factor superfamily } \\
5\end{array}$ & 648 & 3 & 5 & nscaf2674 & TNF superfamily & 2 & 0 & sw08247 & 0.23 \\
\hline BmTNFSF13 & $\begin{array}{l}\text { Tumor Necrosis Factor superfamily } \\
13\end{array}$ & 492 & 3 & 5 & nscaf2674 & TNF superfamily & 3 & 0 & sw13698 & $3 e-06$ \\
\hline BMTRAF3 & TNF-receptor-associated factor 3 & 1479 & 9 & 14 & nscaf2953 & MATH superfamily & 1 & 0 & sw04672 & $1 e-43$ \\
\hline BMTRAF6 & TNF-receptor-associated factor 6 & 1080 & 6 & 13 & nscaf1898 & MATH superfamily & 0 & 0 & sw03276 & $2 e-62$ \\
\hline
\end{tabular}


27 , and 28. The number of exons in the genes varied from one to dozens. The comparing key apoptosisrelated gene numbers in various species (Table 2) shows that there are fewer homologous genes in insects than in the higher eukaryotes. Many important genes in apoptosis pathways were cloned and identified, such as $B m A$ paf-1, BmP53, BmHtra2, and BmEndo $G$ (Table 1 and Additional file 2). However, we did not find homolog hits for many genes in our silkworm databases, including almost all genes of the Bcl-2 and TNFSF families, and caspase-6/-7, Hid, Grim, and Sickle of the RHG family (detailed in Additional file 3 table A). Detailed analysis of primary families and genes involved in apoptotic pathways follows.

\section{Caspase family members in silkworm}

Caspase are a family of cysteinyl aspartate proteinases with two main branches: the pro-inflammatory ICE-like subfamily, previously found only in vertebrates [62], and the apoptotic caspase subfamily. All caspases, normally present as inactive proenzymes in cells, have three different regions: N-terminal prodomains, a large catalytic domain (approximately $20 \mathrm{kD}$, known as P20) and a small catalytic domain (approximately $10 \mathrm{kD}$, known as P10). Based on the length of the prodomain, caspases are divided into two groups: class I (initiators), which have a relatively long prodomain, and class II (effectors), which have a short prodomain (Figure 1). Based on the $\mathrm{N}$-terminal prodomain, the initiators can be divided further into two categories: one class containing a caspase recruitment domain (CARD), such as caspase-2 and -9 in mammals and DRONC in fruit flies, and the other possessing a death effector domain (DED), such as caspase- 8 and -10 in mammals. The mammalian caspase- 8 is replaced functionally by the Drosophila homologue DmDredd, while DmDredd does not have a DED in its N-terminal prodomain [63,64] (Figure 1).

Five caspase family homologs were cloned from the silkworm, including 2 initiators (BmDredd and BmDronc), and 3 effectors (BmCaspase-1, BmICE, and BmCaspase- $N$; Figure 2). The phylogenetic tree of caspase family members in silkworm and other species showed that all the intiator and effector homologs are clustered into group I and group II, respectively. The initiator caspases containing DED domain are clustered into group I, while others containing CARD domain and DmDecay into the other subgroup (Figure 2). The results reveal that the caspase family members are functionally conserved between species.

\section{Silkworm initiator caspase homologs BmDronc and BmDredd}

Caspase-9 has a crucial role during apoptosis from nematodes to mammals. Recently, Dronc (Drosophila Nedd2-like caspase) homologs have been identified in the genomes of Aedes aegypti and Anopheles gambiae (GenBank Accession: 1278470) [65]. The mammalian caspase-9 homolog BmDronc was identified in silkworm, which has two splice variants with common translation initiation and termination sites, named BmDroncL (415 aa) and BmDroncS (183 aa) respectively, and verified by cloning from silkworm BmE cells (Figure 1). Only BmDroncS has a CARD domain and a small subunit, while BmDroncL has the typical caspase family domains (Figure 1). The sequence identities of silkworm BmDroncL with homologs from Homo sapiens, Drosophila melanogaster, and Aedes aegypti are 24\%, 29\% and $35 \%$, respectively.

An ortholog of Drosophila Dredd was also found in the silkworm, named BmDredd (1950 bp, 543aa, figure 1), consistent with the data submitted to NCBI (GeneID: 100141428). The result of domain prediction revealed that BmDredd, AeDredd and DmDredd have long prodomains but no domains that mark them as initiator caspases (Figure 2), unlike mammalian caspase-8 with DEDs. The genetic relationship between caspases from silkworm, Aedes aegypti and Drosophila is much closer than with other species (Figure 2). The sequence identities and

Table 2 Comparision of the key families and genes involved in apoptosis in mammals, Drosophila, Nematode, Echinoids, silkworm and fish

\begin{tabular}{|c|c|c|c|c|c|c|}
\hline Species name Families/genes'name & Mammal $^{\mathrm{a}}$ & Fruit Flies $^{\mathbf{b}}$ & Nematode $^{c}$ & Echinoids $^{d}$ & Silkworm ${ }^{\mathrm{e}}$ & Fish $^{f}$ \\
\hline TNFSF $^{A}$ & 50 & 2 & 0 & 11 & 2 & 11 \\
\hline Caspase Family $^{B}$ & 13 & 7 & 4 & 34 & 5 & 12 \\
\hline $\mathrm{Bcl}-2$ Family ${ }^{\mathrm{C}}$ & about 20 & 2 & 3 & 10 & 1 & 13 \\
\hline Bir Domain ${ }^{D}$ & 7 & 4 & 2 & 7 & 4 & 5 \\
\hline $\mathrm{RHG}^{\mathrm{E}}$ & 0 & 4 (each1) & 0 & 0 & 1 (reaper) & 0 \\
\hline $\mathrm{P} 53^{\mathrm{F}}$ & 1 & 1 & 1 & 1 & 1 & 1 \\
\hline Apaf-1 ${ }^{G}$ & 1 & 1 & 1 & 1 & 1 & 1 \\
\hline
\end{tabular}

In this study Homo sapiens represents mammals, Drosophila melanogaster represents fruit flies, Caenorhabditis elegans represents nematodes, Strongylocentrotus purpuratus represents Echinoids, Bombyx mori represents silkworms, and Danio rerio represents fish. The TNF family comprised of the ligands and the correspondent receptor. $a A$ data are from [76-78]; $a B$ data are from [79]; bB, $c B, b C$ and $c C$ data are from [65] and [6]; dA-dD and fA-fC data are from [80] and [81], respectively. The other data are the results of BLAST searches with the database in NCBI. 


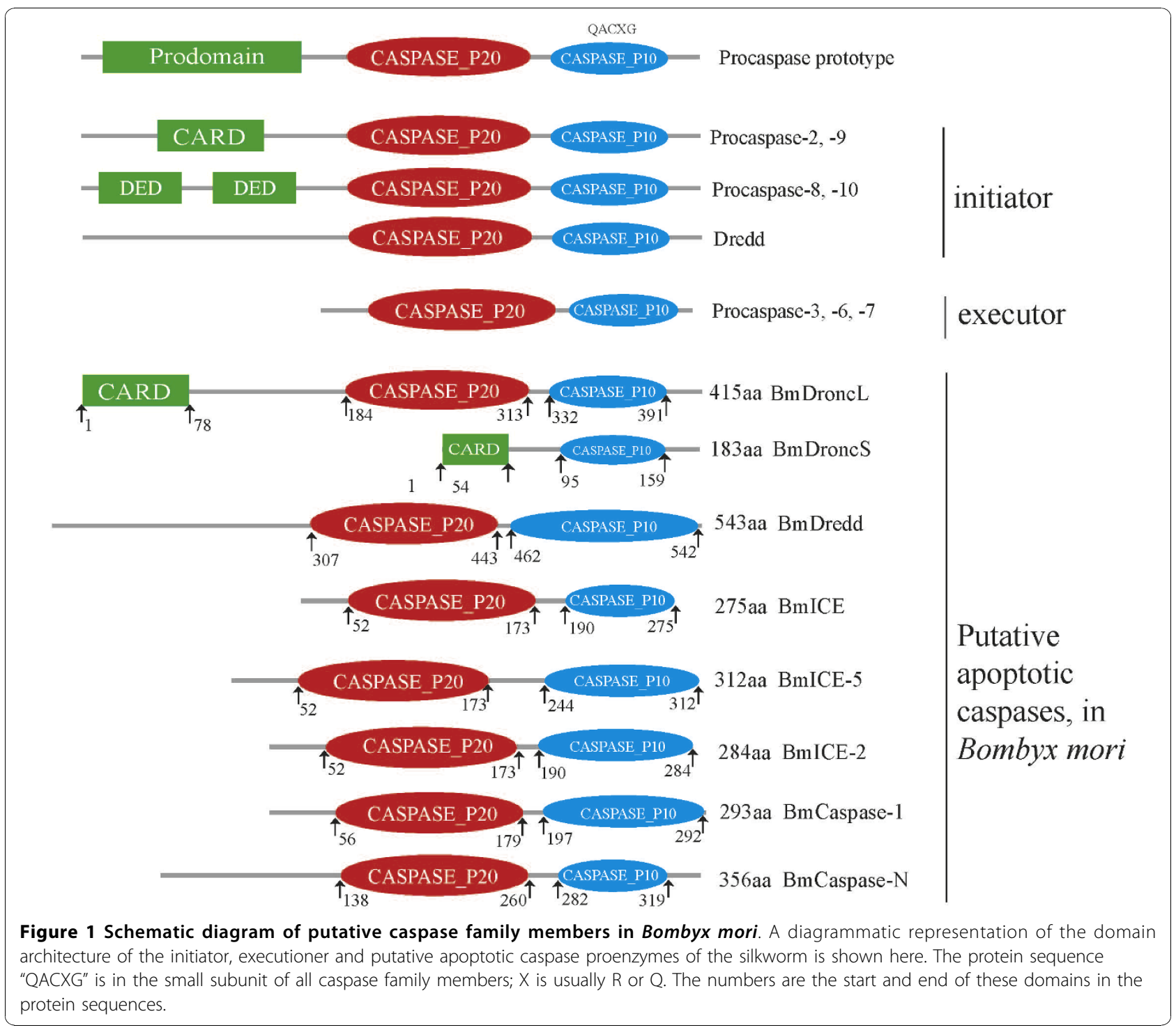

similarities of BmDredd with DmDredd and AeDredd are $28 \%$ and $45 \%, 27 \%$ and $45 \%$, respectively.

\section{Silkworm effector caspases}

Bmcaspase-1 is the first effector caspase reported in Bombyx mori. Pei and colleagues [51] identified Bmcaspase-1 (GeneBank Accession: AF448494) from Bombyx mori $\mathrm{BmN}$ cells. Bmcaspase-1 has only one exon, is 1291 bp long, coding for 293aa, and is located on chromosome 10 (Table 1). Bmcaspase-1 has the classic short prodomain, with the characteristic QACXG sequence in the large subunit (residues 56 - 179) and the small subunit (residues 197 - 292; Figure 1). From the evolutionary relationship, BmCaspase- 1 clusters into the same group with DmICE and DmDcp-1 of Drosophila melanoganster (Figure 2). Duan and colleagues [52] identified
BmICE (275 aa, GeneBank accession: AY88522) from the Bombyx mori integumentum, and Song and colleagues [53] have cloned BmICE-2 (284 aa) and BmICE-5 (312 aa; GeneBank accession numbers DQ360829 and DQ360830, respectively) according to the sequence submitted by Duan [52] from BmE cells. All these genes have the characteristic QRCAG sequence and the typical large/small subunit configuration of caspase family members (Figure 1). We aligned and analyzed the sequences of these three coding sequences with the silkworm $9 \times$ genome database, and the result reveals that $B m I C E, B m I C E-2$ and BmICE-5 have the same translation and termination sites (Additional file 4). BmICE has seven exons, BmICE-2 has eight exons and BmICE5 has nine exons; the splicing differences occur after the seventh exon (Additional file 4). 


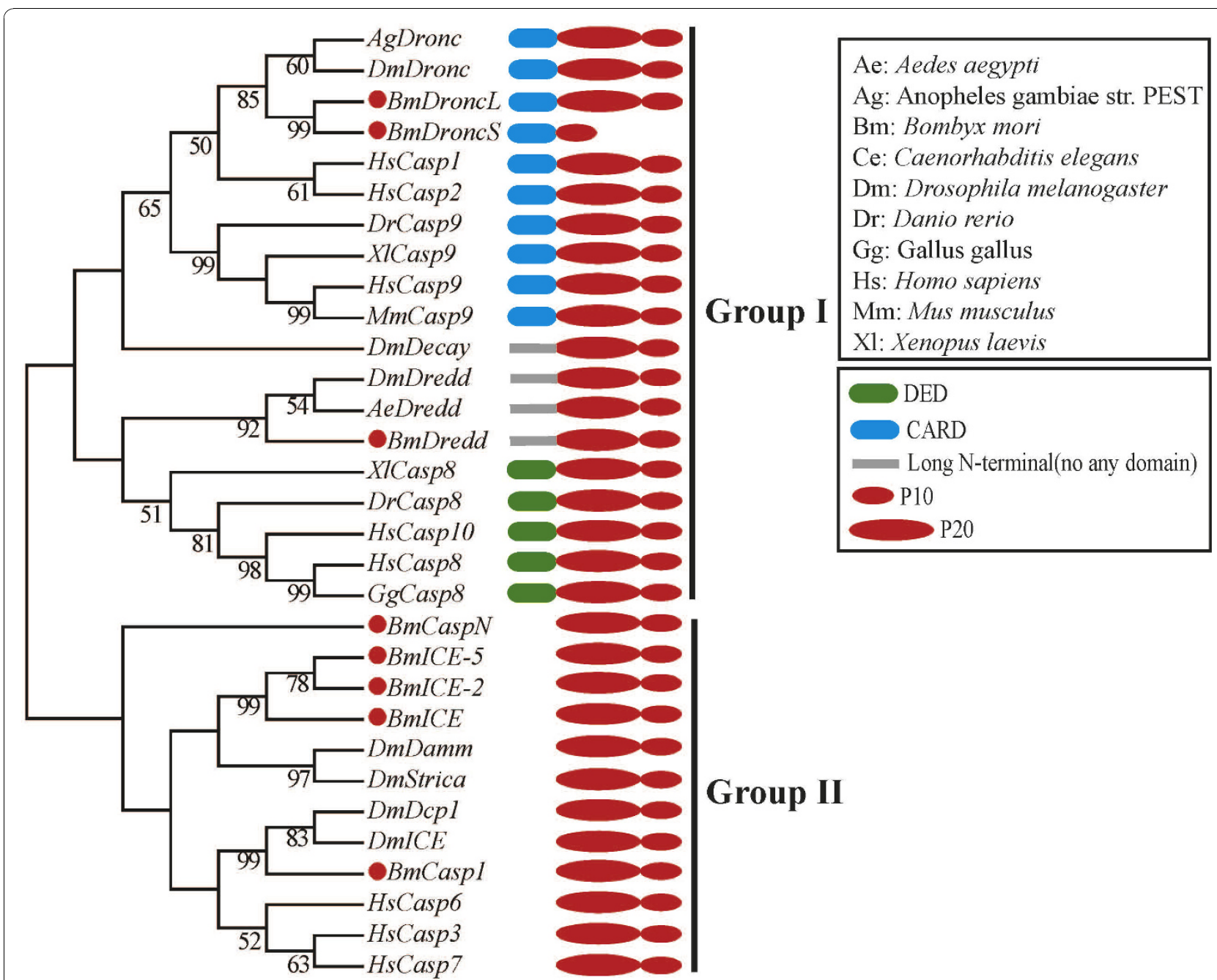

Figure 2 The caspase family tree and domain architecture. Multiple sequence alignments were performed using musle.exe. The neighborjoining tree was produced using MEGA4.0. The putative caspase family members identified in Bombyx mori are marked with large red dots. The domain architectures and the full species names are listed in the black frame on the right.

Our results demonstrated that there is an additional caspase family member in Bombyx mori. Because it has not been reported in Bombyx mori previously, we named it BmCaspase-New (BmCaspase-N). Bmcaspase-N is 1071 bp long, coding for $356 \mathrm{aa}$, and possesses the characteristic structure of caspase effector subfamily members, including a short prodomain and CASc domain with the QACXG sequence. Phylogenetic analysis revealed that Bmcaspase- $N$ clusters into the effector group (Figure 2). Thus we propose that BmCaspase- $N$ belongs to the effector caspase subfamily.

\section{Bcl-2 family members in silkworms}

Bcl-2 family members participate at a crucial point in apoptotic pathways. All members share at least one of four $\mathrm{BH}$ domains (BH1, BH2, BH3 or $\mathrm{BH} 4)$. Tambunan and colleagues [49] identified BmP109 from samples obtained during silk gland histolysis, a stage of Bombyx mori metamorphosis. However, the function of BmP109 with all four conserved $\mathrm{BH}$ regions has not been confirmed in Bombyx mori.

We analyzed and cloned the other Bcl-2 family homo$\log$ BmBuffy, whose structure is more similar to Buffy of Apis mellifera and bcl-2 of Pediculus humanus corporis (Figure 3). BmBuffy lacks the BH4 domain. The completed BmBuffy cDNA is $1632 \mathrm{bp}$, coding for 292 aa, and the relative predicted molecular mass is $32.38 \mathrm{kDa}$. The sequence similarity and identity are $51 \%$ and $27 \%$, respectively, compared with DmBuffy.

\section{BIR domain family members in silkworms}

The BIR domain is a unique structure originally identified in IAP proteins from baculoviruses. At least one BIR motif 

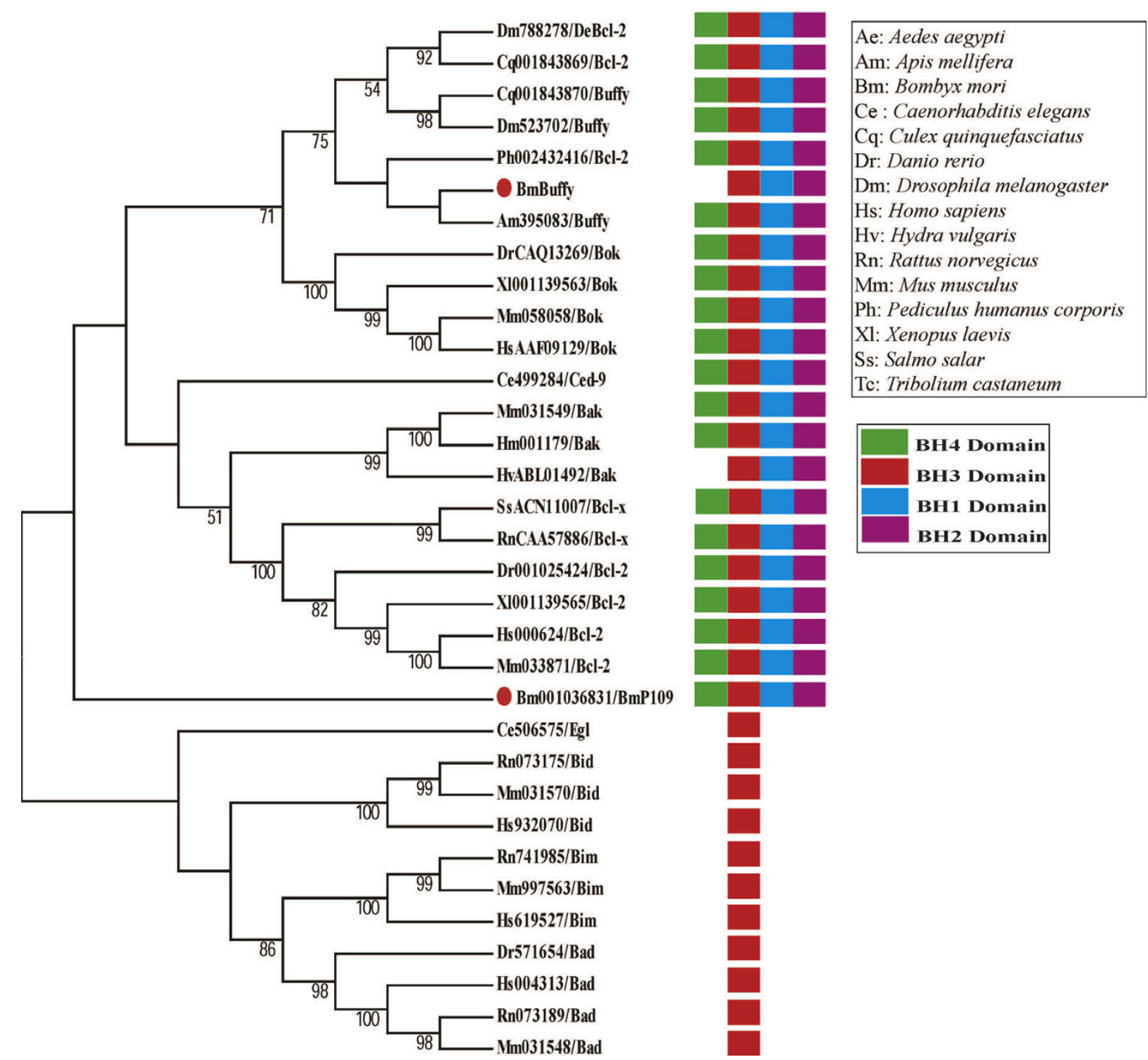

Figure 3 Phylogenetic analysis of Bombyx mori Buffy with homologs in other species and their domain architectures. Multiple sequence alignments were performed using musle.exe. The tree was produced using the neighbor-joining method. The putative Bcl-2 family members identified in Bombyx mori are marked with large red dots. The protein names use an abbreviation of species and gene names. The domain architectures and the full species names are listed in the black frame on the right.

is essential for the antiapoptotic activity of IAP family members, but not all BIR-containing proteins (BIRPs) are IAPs [56]. We identified four proteins containing BIR domains in Bombyx mori, including two IAPs, one Bruce and one survivin. Huang and colleagues [50] cloned the first IAP family member BmIAP from Bombyx mori $\mathrm{BmN}$ cells. BmIAP is a specific inhibitor of mammalian caspase9, but does not directly inhibit the downstream effector proteases caspase- 3 and caspase-7. BmIAP inhibits apoptosis induced by Bax but not Fas in vitro. However, the function of BmIAP in vivo is not yet known. The other IAP family member BmIAP2 is located on the same chromosome as BmIAP, is 561 aa long and possesses three BIR domains and one $\mathrm{Zn}^{2+}$-finger domain. Compared with DIAP1 and DIAP2, BmIAP1 and BmIAP2 have two and three BIR domains, respectively, also (Figure 4). The BmBruce and survivin proteins each have one BIR domain, with a sequence consistent with the online BIR sequence (http://www.expasy.org/cgi-bin/nicedoc.pl?PS50143), and are 4236 aa and 136 aa long, respectively (Figure 4). Besides their size difference, BmBruce also has an ubiquitin-proteasome binding motif, which is homologous to Drosophila Bruce protein [66].

RHG family members in Drosophila contain the IAPBinding-Motif (IBM) domain in their N-terminal, which binds to and removes the inhibitory activity of IAP 


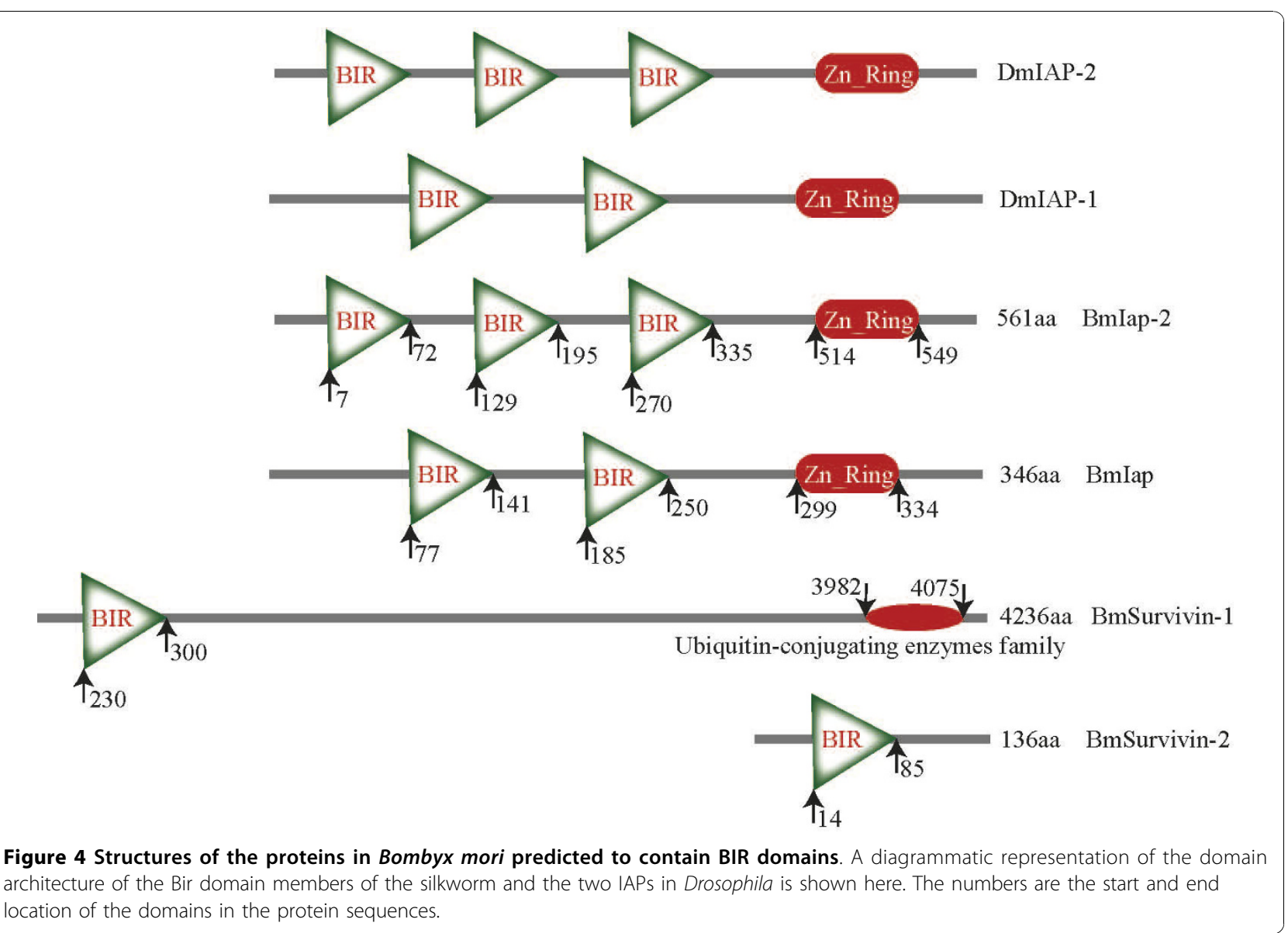

$[21,28,67]$ as well as their structural and functional homologs Smac/Diablo in mammals [68]. However, RHG family proteins connect many different signaling pathways, thereby having a central role in the regulation of programmed cell death in Drosophila, which is very different from other species, especially compared to mammalian Smac/Diablo [69]. Another IAP inhibitor, Htra2/ Omi in mammals and its homolog protein DmHtra/Omi in Drosophila, have a function similar to Smac/Diablo. DmHtra2/Omi in Drosophila also has serine protease activity. Interestingly, reducing DmOmi expression by RNAi in the fly inhibits stress-induced apoptosis, while the neurodegeneration is increased in the Htra2/Omi knockout mouse [28]. The homolog BmReaper, an ortholog of Drosophila reaper, was found in silkworm [54]. BmReaper has both IBM and GH3 domain, which can bind to BmIAP and induce apoptosis in insect cells. The homolog BmHtra2 was also found in the silkworm and cloned (Additional file 2).

\section{TNFSF and their receptors in silkworm}

TNF family ligands and their corresponding receptors (TNFR) have pivotal roles in many important physiological processes, such as host defense, inflammation, apoptosis, autoimmunity and immune system organogenesis. The TNF-related ligands are type II (intracellular $\mathrm{N}$-terminus) transmembrane proteins containing a TNF homology domain (THD) at the extracellular C terminus. Protein sequences of 18 TNFSF ligands in mammals [70] and the TNF ligand Eiger in Drosophila [62] used as queries were aligned with the silkworm predicted protein database by BlastP. Two TNFSF members, $\mathrm{Bm} 3585$ and $\mathrm{Bm} 3614$, were identified. They are located on chromosome 5 (Table 1). Bm3585 and Bm3614 possess the typical THD as predicted (http:// blast.ncbi.nlm.nih.gov/; Table 1), and demonstrated that potential TNF ligands are present in Bombyx mori. The phylogenetic tree of TNFSF between silkworm and other species show that Bm3614 and the insect Eiger homolog are in one cluster, while Bm3585 and TNFSF5 are classified close together, but the two TNF ligand homologs are evolutionarily distant (Figure 5), all of which indicate that a gene deletion or duplication event might had happened.

Using sequence information from 31 TNFR superfamily (TNFRSF) proteins [70] from mammals and one TNFRSF protein from insects, a search for possible TNF receptors was performed in Bombyx mori, but no match 


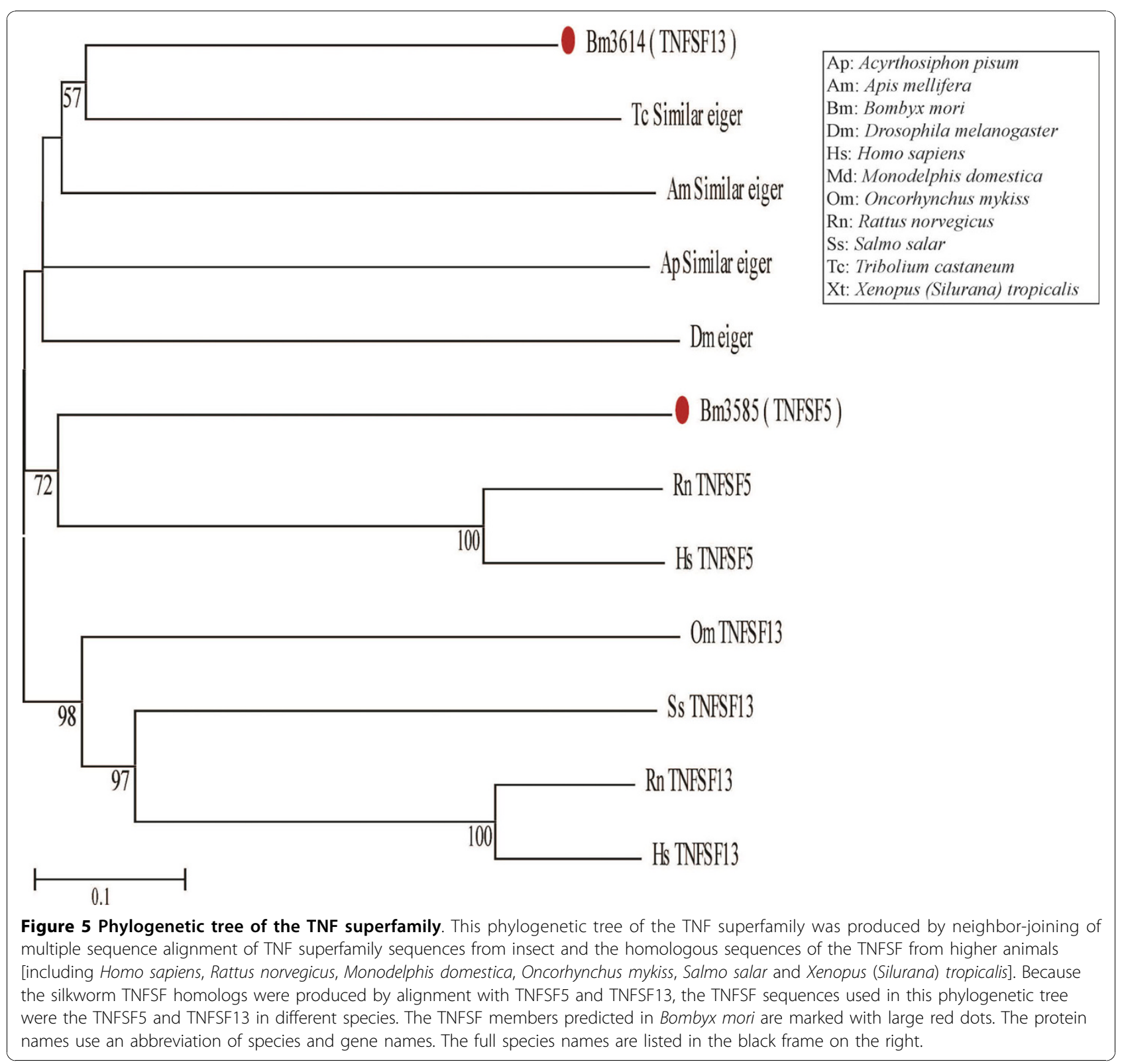

to the TNFR domains was found. However, many predicted proteins (mainly transmembrane proteins, fiber proteins, or mucous membrane proteins) possessed all the structural motifs, such as a cysteine-rich domain, $\mathrm{Ca}^{2+}$-binding site, and receptor/ligand interaction site (data not shown), but did not meet our criteria. However, homologs containing DDs (death domains) such as $B m D a x x$ and BmFadd, were found in the silkworm.

\section{Expression profiles of apoptosis-related genes in silkworm \\ ESTs analysis}

In order to detect the expression of the Bombyx mori apoptosis-related genes, we searched the silkworm
dbEST database downloaded from GenBank using the putative coding sequences as queries. Forty apoptotic genes matched at least one EST. Nine genes had complete expressed sequence tags (ESTs), and the remaining genes had incomplete ESTs (Table 1).

\section{Microarray-based gene expression profiles in different} development stages

To analyze the expression of the silkworm apoptosisrelated genes in different developmental stages according the chips, a BlastN alignment was performed using the silkworm different developmental stage database. The results indicated that all the apoptosis-related genes contained at least one oligonucleotide probes except BmDredd, BmFadd, BmGsk3 (Table 1), for which no 
probe was found. Only 26 apoptosis-genes show higher expression than in the 3rd day of the fifth instar, when almost all genes expressed in the silkworm are present (Figure 6). The results revealed that the expressions of apoptosis-genes are relative low in silkworm.

\section{The identification of apoptosis-related genes in silkworm}

To test the expression of the apoptosis genes, we designed primers for 32 genes according to their predicted DNA sequences (Additional file 2) and carried out RT-PCR using the cDNA isolated from the different development stages of silkworm and BmE cells exposed to different stressors as described in the Methods section. Twenty three of all apoptosis-related genes tested were cloned and sequenced, five apoptosis-related genes were detected by RT-PCR but not sequenced successfully, although the PCR product sizes were consistent with the predicted sizes, and four silkworm apoptosis-related genes were not detected (Additional file 2). Overall, the expression of these genes, except a few, was relatively much lower than BmActin3 expression (Figure 7). The results show that most of the key apoptosis-genes in silkworm are expressed, which revealed that these potential apoptosis-genes are present in Bombyx mori.

\section{Discussion}

\section{The silkworm apoptosis-related genes}

In this study, we identified and cloned 52 silkworm apoptosis-related genes, including homologs of almost all the key genes involved in apoptosis pathways in other species. The fact that the BH3-only subfamily only existed in vertebrates, while the RHG family is found only in insects, reveals conservation within species and the variability among the species, although their functional homologs exist in mammals. Moreover, the main families of apoptosis-related genes exist in all model organisms, but the gene numbers in some species (such as the caspase family in Strongylocentrotus purpuratus) are much higher, indicating that expansion might have occurred in these species, most likely due to environmental stress.

The key genes involved in apoptosis pathways in Bombyx mori are described in detail in Table 1. Interestingly, TNFSF members containing DDs, caspase family members involved in inflammation, and the BH3-only Bcl-2 family members are not found in Bombyx mori. However, the silkworm not only has an insect Eiger homolog $B m 3614$, but also has $B m 3585$, which is similar to mammalian TNFSF5, neither of which have been reported in either Drosophila or mosquito. These results suggest that some genes may be lost in evolution. The new putative effector caspase Bmcaspase- $N$ was found in silkworms, but not in mosquitoes [71] or Drosophila, suggesting that gene expansion occurred in Bombyx mori after the insect diverged from the common ancestor. For example, since BmDroncS only has a CARD and a small subunit that lacking the core active site, it may act as a caspase-like decoy molecule [72]. Furthermore, the phylogenetic analysis of caspase family members in Bombyx mori with those involved in apoptotic pathways in other species shows that caspase- 8 homologs lacking DED domains in insects are clustered into the same class, which suggests that the caspase- 8 homology gene mutation might have occurred after divergence of animals and insects. In contrast, the presence of all caspase- 9 homologs in the same class suggests caspase- 9 is highly conserved from insects to mammals (Figure 2). In addition, BmBruce has an ubiquitin-proteasome binding motif, which suggests that the ubiquitin-proteasome pathway may be present in Bombyx mori, as in Drosophila [69].

\section{The possible apoptosis pathways of Bombyx mori}

The apoptosis-related factors identified in silkworms cover almost all the critical junctions in the apoptosis pathways of other model organisms. Although Fas and its receptor were not found, we found some proteins predicted containing cysteine regions, $\mathrm{Ca}^{2+}$ binding sites, or the typical receptor/ligand interaction sites of TNFRSF members (data not shown), downstream genes such as BmTraf family members and BmFadd, which contain DDs, and BmDredd. All these results suggest that the death receptor pathway may be present in Bombyx mori. We hypothesize that the epidermal growth factor pathway also exists in Bombyx mori, because homologs of the mammalian members of this pathway were cloned and identified in Bombyx mori, including BmRaf, BmRas, BmPka, BmPkc, BmErk, BmPi3k, BmStat, BmAkt, BmGsk3, and BmFkhr. The Bombyx mori homologs of Cyt C, Apaf-1, Caspase-9, Aif, Endo $G$, and Htra2 were identified and characterized in Bombyx mori, and Kumarswamy and colleagues [29] and the Pan group [30] have demonstrated cytochrome $C$ release into the cytoplasm in stress-induced apoptotic Sf-9 and BmE cells. Therefore, the mitochondrial apoptotic pathway may be functional in Bombyx mori. Furthermore, the DmReaper orthologs found in Bombyx mori indicate that this apoptotic gene is conserved between species. In addition, key genes in the DNA damage response pathway, like BmP53 and BmSir2, are also identified, so we hypothesize that the DNA damage pathway is also functional in Bombyx mori. In conclusion, the intrinsic and extrinsic pathways described in other models may potentially exist in Bombyx mori.

In 1965 silkworm hemolymph was used as an additional agent in cell culture in vitro [73]. Rhee and colleagues confirmed that silkworm hemolymph inhibited cell apoptosis not only in a baculovirus-induced insect cell system [35] but also in a human cell system [36]. In 2002, this group reported that they isolated and characterized an apoptosis-inhibiting hemolymph component 


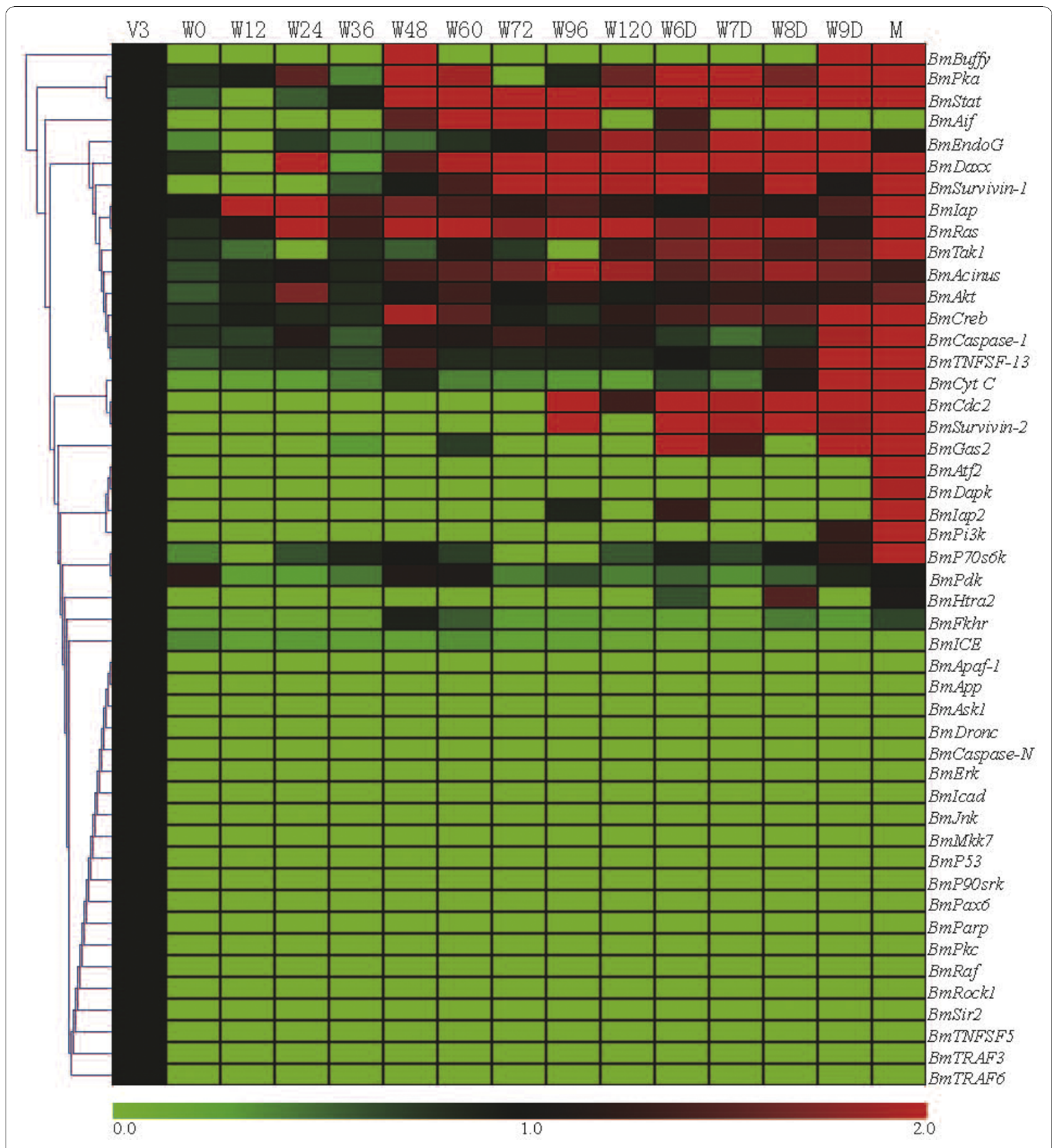

Figure 6 Microarray analysis of the expression of the putative silkworm apoptosis-related genes during different growth stages. The expression levels of all the genes in different stages compare to their expression level in the $3^{\text {th }}$ day of fifth instar. V3: $3^{\text {th }}$ of fifth instar; W0: $0 \mathrm{~h}$ after wandering; W12: $12 \mathrm{~h}$ after wandering; W24: $24 \mathrm{~h}$ after wandering; W36: $36 \mathrm{~h}$ after wandering; W48: $48 \mathrm{~h}$ after wandering; W60:60 h after wandering; W72: $72 \mathrm{~h}$ after wandering; W96: $96 \mathrm{~h}$ after wandering; W120: $120 \mathrm{~h}$ after wandering; W6D: $6^{\text {th }}$ day after wandering; W7D: $7^{\text {th }}$ day after wandering; W8D: $8^{\text {th }}$ day after wandering; W9D: $9^{\text {th }}$ after wandering; M: silk moth. Red is a ratio $\geq 1$, green is a ratio $\leq 1$, and black is a ratio $=1$.

[34]. Later they constructed a recombinant vector to express the protein and purify it in vitro, and confirmed this protein is one of the $30 \mathrm{~K}$ proteins isolated from silkworm hemolymph used to minimize cell death. They speculated that the $30 \mathrm{Kc} 6$ protein inhibits the apoptosis by involvement upstream of caspase 3 activation $[37,38]$. Therefore, there might be differences between Bombyx mori and other models in the regulation of apoptosis. 


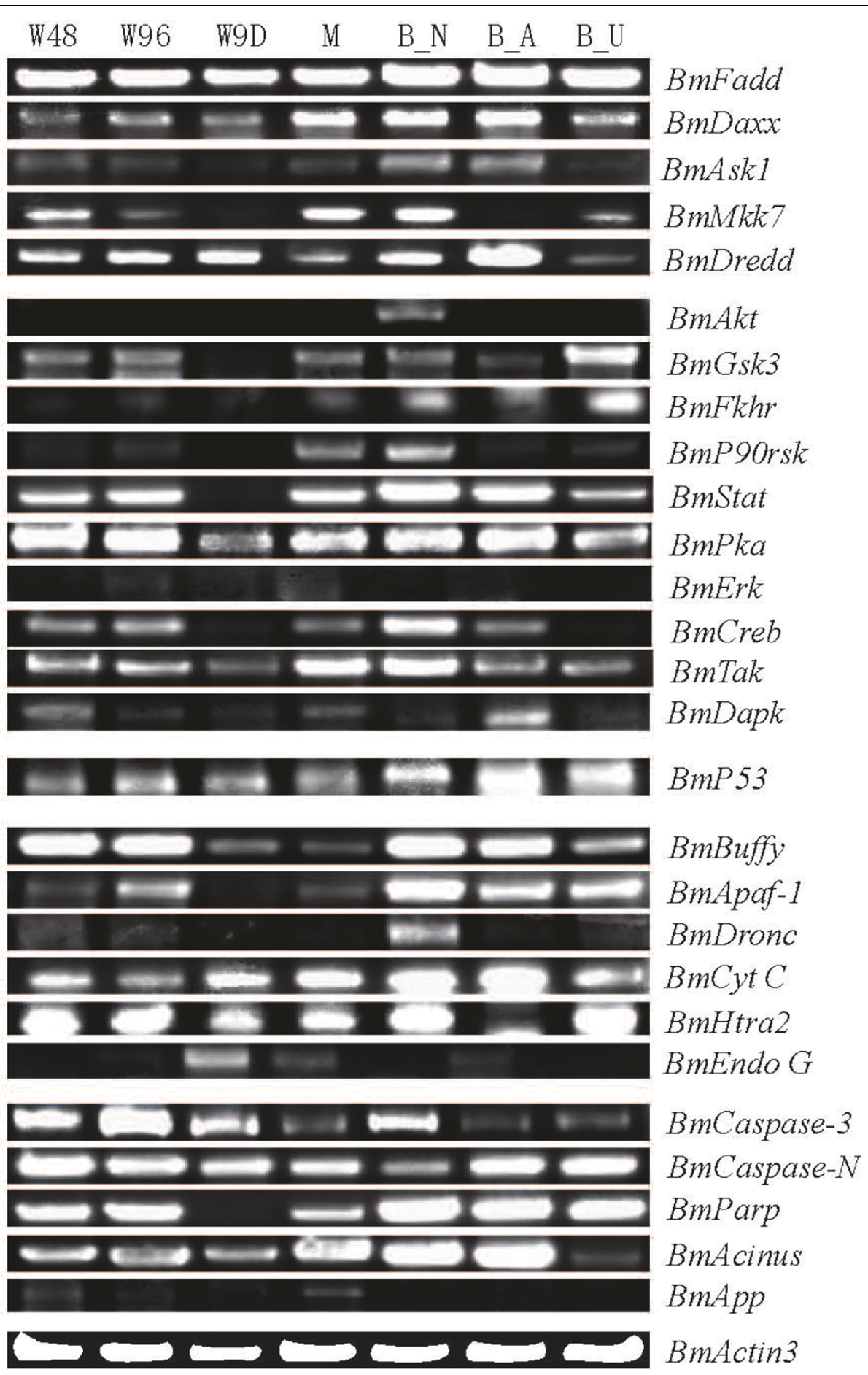

Figure 7 RT-PCR analysis of the expression of the putative silkworm apoptosis-related genes during different growth stages and in BmE cells. Total RNA was isolated as described in the Methods section and analyzed by RT-PCR. W48: about $48 \mathrm{~h}$ after wandering; W96: about $96 \mathrm{~h}$ after wandering; W9D: about $9^{\text {th }}$ day after wandering; M: silk moth; B_N: normal BmE cells; B_A: BmE cells exposed to actinomycin D; B_U: BmE cells exposed to UV irradiation.

Questions remain as to the precise regulation of apoptosis in Bombyx mori: for example, the central role of BmReaper, as well its homolog in Drosophila, and whether $B m C y t C$ is released from the mitochondria as in mammals. Also, the BH3-only Bcl-2 family members that link the two primary apoptotic pathways are not found in Bombyx mori and have not been reported in insects. Identification of a surrogate protein that 
performs the same function would provide great insight into apoptosis in the silkworm.

\section{Conclusions}

Biochemical evidence and comparative genomic analyses with mammals and other organisms show that many apoptosis-related gene homologs are present in Bombyx mori, and suggest that the typical apoptotic pathways exist in Bombyx mori. The identification of these new genes in Bombyx mori further supports the universality of apoptotic mechanisms. The data in this study provide an overview for putative apoptosis-related genes in Bombyx mori, which should contribute to mechanistic studies of apoptosis in Bombyx mori in the future.

\section{Methods}

\section{Cell line and Bombyx mori}

The BmE (Bombyx mori Embryo) cell line BmE-SWU1 [74] was cultured in Grace medium containing $10 \%$ fetal bovine serum (FBS) at $27^{\circ} \mathrm{C}$ in an incubator. The Bombyx mori DaZao strain larvae were bred with fresh mulberry leaves at $25^{\circ} \mathrm{C}$ with a $12 \mathrm{~h}: 12 \mathrm{~h}$ photoperiod.

\section{Identification of silkworm apoptosis-related genes}

The databases used for the Bombyx mori genomic information include Bombyx mori 9x genomic sequencing database, Bombyx mori EST database, CDS database, and predicted protein database (all found through http:// silkworm.swu.edu.cn/silkdb/). The nucleotide and protein sequences of apoptosis-related homolog of different species (including Bombyx mori, Drosophila melanogaster, Caenorhabditis elegans, Homo sapiens) were obtained from the NCBI database (http://www.ncbi.nlm. nih.gov) (described in detail in Additional file 3 Table B).

For the comparison analysis, the gene sequences, mRNA sequences, and protein sequences of apoptosisrelated gene homologs in various sepecies were downloaded from NCBI. Three methods were used as follows:

1. The protein sequences of apoptosis-related genes as queries were aligned with the predicted protein database by the BlastP program using amino acid sequence homology and an E-value of 0 (to account for the large differences between species). Predicted silkworm genes in the comparison results were selected to compare with the NCBI protein database (http://blast.ncbi.nlm. nih.gov/Blast.cgi) for further confirmation. If the predicted gene contained the same domains as its homo$\log$ and the first genes in the alignment result is the homolog in other species, then the predicted gene was considered a homolog in silkworm.

2. The sequences of the conserved domains of the gene intercepted were used as queries to perform BlastP searches against the silkworm predicted protein database and TBlastN searches against the silkworm $9 x$ genome sequence using an E-value of 0 . The identification is the same as described above. (TNFSF family members, BH-3 only subfamily members and RHG family members were analyzed using this method.)

3. Apoptosis-related genes not found in the silkworm database, were searched against the silkworm EST database by TblastN program using an E-value of 0 . A method of cloning electronically was used, and we confirmed the result as above. (BmBuffy was checked using this method)

Finally, to acquire detailed information about the predicted gene, all the putative apoptosis-related genes in Bombyx mori were aligned with the 9x silkworm genomic database, EST database, and the microarray chip databases for different developmental stages using the BlastN program.

\section{Domain prediction, multiple sequence alignments and phylogenetic tree construction}

All the domains of the putative apoptosis-related genes of the silkworm Bombyx mori are predicted (http://blast. ncbi.nlm.nih.gov/Blast.cgi) or (http://www.expasy.org/ prosite/). Multiple sequence alignments were carried out using Clustal W or Muscle.exe programs. Phylogenetic analyses were performed using MEGA version 4.0 [75].

\section{Treatments and RNA extraction}

BmE cells were exposed to $200 \mathrm{ng} / \mathrm{ml}$ actinomycin D for $12 \mathrm{~h}$ or irradiated for $70 \mathrm{~s}$ with $30 \mathrm{~J} / \mathrm{m}^{2} \mathrm{UV}$, and then cultured normally for another $12 \mathrm{~h}$. Larva [approximately 48 hours after wandering (spinning just finished)], pupa [approximately 96 hours after wandering (newly formed) and on approximately the 9th day after wandering (the day before becoming a moth)], and the adult moth were collected, and frozen immediately in liquid nitrogen. Total mRNA was extracted using Trizol reagent (Invitrogen, USA), and DNA contamination in the mRNA samples was digested with RNase-free DNase I (Takara, Japan). The concentration of RNA was calculated by spectrophotometry (Gene Spec V; HITACHI, Japan). The first strand of cDNA was synthesized from $1 \mu \mathrm{g}$ mRNA using M-MLV Reverse Transcriptase following the manufacturer's instructions (Promega, USA).

Verification of the putative silkworm apoptosis-related genes The PCR primers were designed based on the coding sequences of the putative silkworm apoptosis-related genes identified by the bio-informatics analysis (Additional file 2). Silkworm cytoplasmic actin A3 gene (forward primer: 5'-AAC ACC CCG TCC TGC TCA CTG-3'; reverse primer: 5'-GGG CGA GAC GTG TGA TTT CCT-3') was used as an internal control. PCR amplification was 
performed in a total reaction volume of $25 \mu \mathrm{l}$, containing normalized cDNA ( $6 \mu \mathrm{g}$ cDNA except BmActin3 using 3 $\mu \mathrm{g}$ cDNA), 15 pmol of each primer $(1 \mu \mathrm{l}), 2 \mathrm{mM} \mathrm{MgCl}_{2}(2$ $\mu \mathrm{l}), 0.25 \mathrm{mM}$ dNTP $(2 \mu \mathrm{l}), 1 \times$ buffer $(2.5 \mu \mathrm{l}), 2.5$ units of Taq DNA polymerase and distilled deionized $\mathrm{H}_{2} \mathrm{O}$. PCR was performed as follows: initial denaturation at $94^{\circ} \mathrm{C}$ for $3 \mathrm{~min}$, followed by 25 cycles of $30 \mathrm{~s}$ each at $94^{\circ} \mathrm{C}, 1 \mathrm{~min}$ annealing (at the temperatures listed in Additional file 2), 1-3 min extension at $72^{\circ} \mathrm{C}$ (the time depends on the length of the gene), and a final extension at $72^{\circ} \mathrm{C}$ for $10 \mathrm{~min}$. The amplification products were analyzed on $1 \%$ agarose gels, and sequenced and confirmed by the Ying Jun Company and Bio-engineering (Shanghai, China).

\section{Analysis of apoptosis-related genes of different developmental stages}

More than 184201 ESTs from Bombyx mori are available in the NCBI database. To search transcripts for individual apoptosis-related genes, a BlastN search was conducted against the silkworm EST database. The putative coding sequences were used as queries. A $95 \%$ or greater identity and minimum cut-off E-value (less than or equal to e-20) were employed to discriminate between duplicated genes. Microarray data analysis was performed as described by Xia and colleagues [59].

\section{Additional material}

Additional file 1: The IDs of genes identified in the genomic database of silkworm. Table A - The IDs of Genes submitted previously. All these genes submitted to NCBI and their Gls were listed in the table. And these genes were submitted by us in the table $\mathrm{A}$, while that have been submitted by others in the table B. " + " represents reported genes, while "-" represents genes not reported but only submitted to NCBI (see the comments for table B). Table B - The IDs of new identified Genes.

Additional file 2: The primers and annealing temperatures of apoptosis-related genes in the silkworm. Genes cloned and sequenced successfully are labeled "sequencing success," while genes cloned but not sequenced successfully are labeled "PCR success." Those genes neither cloned nor sequenced successfully are labeled "-".

Additional file 3: The apoptosis-related genes not searched in silkworm database and sequences aligned as queries. Table $A$ - The main genes homology not searched in silkworm were listed in the table. Table B - The sequences as queries. Because of limited space in the manuscript, partial genes' sequences in various species are displayed. The silkworm apoptotis-related genes and their protein accession included in NCBI are presented in red and bolded

Additional file 4: Three different splice variants of BmICE in Bombyx mori. 1,2 and 3 are the splice variants of BmICE, named BmICE, BmICE-5 and BmlCE-2 respectively.

\section{Acknowledgements}

We are grateful to Dr. Hong-Juan Cui (the Sericultural Laboratory of Agricultural Ministry, Institute of Sericulture and Systems Biology, Southwest University) for her thoughtful critique of the manuscript and providing helpful comments that led to its improvement to submission. This work is supported by grants from the National Basic Research Program of China (No. 2005cb121000), the Hi-Tech Research and Development (863)
Program of China (2006AA10A118), and the National Natural Science Foundation of China (30972146).

\section{Authors' contributions}

JYZ and MHP made the study design, the data collection and analysis. JYZ drafted the manuscript. MHP revised the manuscript. ZYS, SJH and ZSY did partial data analysis. DL and $\mathrm{DHZ}$ helped to perform the experiment of RTPCR. CL conceived of the study, and participated in its design and coordination. All authors read and approved the final manuscript.

Received: 15 February 2010 Accepted: 31 October 2010

Published: 31 October 2010

\section{References}

1. Carl V: Untersuchungen über die Entwicklungsgeschichte der Geburtshelferkröte. 1842, (Alytes obstetricans) 130 (Jent und Gassman).

2. Lockshin RA, Zakeri Z: Apoptosis, autophagy, and more. The International Journal of Biochemistry \& Cell Biology 2004, 36:2405-2419.

3. Kerr J, Wyllie A, Currie A: Apoptosis: a basic biological phenomenon with wide-ranging implications in tissue kinetics. BrJCancer 1972, 26:239-257.

4. Bursch W: The autophagosomal lysosomal compartment in programmed cell death. Cell Death Differ 2001, 8:569-581.

5. Velentzas AD, Nezis IP, Stravopodis DJ, Papassideri IS, Margaritis LH: Apoptosis and Autophagy Function Cooperatively for the Efficacious Execution of Programmed Nurse Cell Death During Drosophila virilis Oogenesis. Autophagy 2007, 3(2):130-132.

6. Colin J, Gaumer S, Guenal I, Mignotte B: Mitochondria, Bcl-2 family proteins and apoptosomes: of worms, flies and men. Frontiers in Bioscience 2009, 14:4127-4137.

7. Salvesen GS, Dixit VM: Caspases: Intracellular Signaling by Proteolysis. Cell Death Differ 1997, 91(4):443-446.

8. Wallach D, Varfolomeev EE, Malinin N, Goltsev Y, Kovalenko A, Boldin M: Tumor necrosis factor receptor and Fas signaling mechanisms. Annu Rev Immunol 1999, 17(1):331-367.

9. Yuan J: Transducing signals of life and death. Curr Opin Cell Biol 1997, 9(2):247-251

10. Schmitz I, Kirchhof S, Krammer PH: Regulation of death receptor-mediated apoptosis pathways. The International Journal of Biochemistry \& Cell Biology 2000, 32:1123-1136.

11. Mehlen P, Bredesen DE: The dependence receptor hypothesis. Apoptosis 2004, 9(1):37-49.

12. Reed JC: Cytochrome c: can't live with it-can't live without it. Cell 1997, 91:559-562.

13. Green D, Reed J: Mitochondria and apoptosis. science 1998, 281(5381):1309-1312.

14. Kroemer G, Galluzzi L, Brenner C: Mitochondrial membrane permeabilization in cell death. Physiol Rev 2007, 87(1):99-163.

15. Foo MMARS-Y: Simplified apoptotic cascades. Heart Fail Rev 2008, 13:111-119.

16. Luo X, Budihardjo I, Zou H, Slaughter C, Wang X: Bid, a Bcl2 Interacting Protein, Mediates Cytochrome c Release from Mitochondria in Response to Activation of Cell Surface Death Receptors. Cell 1998, 94(4):481-490.

17. Li H, Zhu H, Xu Cj, Yuan J: Cleavage of BID by caspase 8 mediates the mitochondrial damage in the Fas pathway of apoptosis. cell 1998, 94(4):491-501.

18. Wang $\mathrm{K}$, Yin $\mathrm{XM}$, Chao DT, Milliman $\mathrm{CL}$, Korsmeyer SJ: BID: a novel BH3 domain-only death agonist. Genes Dev 1996, 10:2859-2869.

19. Gross A, Yin XM, Wang K, Wei MC, Jockel J, Milliman C, ErdjumentBromage H, Tempst P, Korsmeyer SJ: Caspase Cleaved BID Targets Mitochondria and Is Required for Cytochrome c Release, while BCL-XL Prevents This Release but Not Tumor Necrosis Factor-R1/Fas Death. The Journal Of Biological Chemistry 1999, 274(2):1156-1163.

20. White K, Grether M, Abrams J, Young L, Farrell K, Stelle H: Genetic control of programmed cell death in Drosophila. Science 1994, 264(5159):677-683.

21. Oberst A, Bender C, Green DR: Living with death: The evolution of the mitochondrial pathway of apoptosis in animals. Cell Death Differ 2008, 15(7):1139-1146.

22. Dorstyn L, Mills K, Lazebnik Y, Kumar S: The two cytochrome c species, DC3 and DC4, are not required for caspase activation and apoptosis in Drosophila cells. The Journal of Cell Biology 2004, 167(3):405-410. 
23. Dorstyn L, Read S, Cakouros D, Huh JR, Hay BA, Kumar S: The role of cytochrome $\mathrm{c}$ in caspase activation in Drosophila melanogaster cells. The Journal of Cell Biology 2002, 156(6):1089-1098.

24. Dorstyn L, Kumar S: A cytochrome c-free fly apoptosome. Cell Death and Differentiation 2006, 13:1049-1051.

25. Varkey J, Chen P, Jemmerson R, Abrams JM: Altered Cytochrome c Display Precedes Apoptotic Cell Death in Drosophila. The Journal of Cell Biology 1999, 144(4):701-710.

26. Zimmermann KC, Ricci JE, Droin NM, Green DR: The role of ARK in stressinduced apoptosis in Drosophila cells. The Journal of Cell Biology 2002, 156(6):1077-1087.

27. Means JC, Muro I, Clem RJ: Lack of involvement of mitochondrial factors in caspase activation in a Drosophila cell-free system. Cell Death Differ 2006, 13(7):1222-1234.

28. White RJKK: Inside an enigma: do mitochondria contribute to cell death in Drosophila? Apoptosis 2009, 14:961-968.

29. Kumarswamya R, Sethc RK, Dwarakanathb BS, Chandna S: Mitochondrial regulation of insect cell apoptosis: Evidence for permeability transition pore-independent cytochrome-c release in the Lepidopteran Sf9 cells. The International Journal of Biochemistry \& Cell Biology 2009, 41:1430-1440.

30. Pan MH, Chen M, Huang SJ, Yu ZS, Cheng CG, Lu C: Cloning and Protein Release of Cytochrome C in the Apoptosis Cells of Silkworm, Bombyx mori. Scientia Agficultura Sinica 2009, 42(7):2546-2551.

31. Lockshin RA, Williams CM: Programmed cell death-l. Cytology of degeneration in the intersegmental muscles of the Pernyi silkmoth. Journal of Insect Physiology 1965, 11(2):123-133.

32. Butterworth FM, Bodenstein D, King RC: Adipose tissue of Drosophila melanogaster. I. An experimental study of larval fat body. Journal of Experimental Zoology 1965, 158(2):141-153.

33. Iga M, Iwami M, Sakurai S: Nongenomic action of an insect steroid hormone in steroid-induced programmed cell death. Molecular and Cellular Endocrinology 2007, 263:18-28.

34. Kim EJ, Rhee WJ, Park TH: Isolation and Characterization of an ApoptosisInhibiting Component from the Hemolymph of Bombyx mori. Biochemical and Biophysical Research Communications 2001, 285:224-228.

35. Rhee WJ, Park TH: Silkworm Hemolymph Inhibits Baculovirus-Induced Insect Cell Apoptosis. Biochemical and Biophysical Research Communications 2000, 271:186-190.

36. Choi SS, Rhee WJ, Park TH: Inhibition of Human Cell Apoptosis by Silkworm Hemolymph. Biotechnol Prog 2002, 18:874-878.

37. Kim EJ, Park HJ, Park TH: Inhibition of apoptosis by recombinant $30 \mathrm{~K}$ protein originating from silkworm hemolymph. Biochemical and Biophysical Research Communications 2003, 308:523-528.

38. Kim EJ, Rhee WJ, Park TH: Inhibition of Apoptosis by a Bombyx mori Gene. Biotechnol Prog 2004, 20:324-329.

39. Choi SS, Rhee WJ, Park TH: Beneficial Effect of Silkworm Hemolymph on a CHO Cell System: Inhibition of Apoptosis and Increase of EPO Production. Biotechnology and Bioegeneering 2005, 91(7):793-800.

40. Zhong BX, Li JK, Lin JR, Liang JS, Su SK, Xu HS, Yan HY, Zhuang PB, Fujii H Possible Effect of 30K Proteins in Embryonic Development of Silkworm Bombyx mori. Acta Biochimica et Biophysica Sinica 2005, 37(5):355-361.

41. Okazaki T, Okudaira N, Iwabuchi K, Fugo H, Nagai T: Apoptosis and Sdhesion of Hemocytes During molting stage of silkworm, Bombyx mori. Zoological Science 2006, 23:299-304.

42. Morishimaa N, Okanob K, Shibataa T, Maeda S: Homologous p35 proteins of baculoviruses show distinctive anti-apoptotic activities which correlate with the apoptosis-inducing activity of each virus. FEBS Letters 1998, 427:144-148.

43. Rhee WJ, Kim EJ, Park TH: Silkworm hemolymph as a potent inhibitor of apoptosis in Sf9 cells. Biochemical and Biophysical Research Communications 2002, 295:779-783.

44. Iwanaga M, Kang WK, Kobayashi M, Maeda S: Baculovirus infection blocks the progression of fat body degradation during metamorphosis in Bombyx mori. Arch Virol 2000, 145:1763-1771.

45. Vier J, Furmann C, Hacker G: Baculovirus P35 Protein Does Not Inhibit Caspase- 9 in a Cell-Free System of Apoptosis. Biochemical and Biophysical Research Communications 2000, 276:855-861.

46. Kundu RDMMSKGSC: Silk sericin protein of tropical tasar silkworm inhibits UVB-induced apoptosis in human skin keratinocytes. Mol Cell Biochem 2008, 311:111-119.
47. Zhou QX, Li YN, Shen XJ, Yi YZ, Zhang YZ, Zhang ZF: The scaleless wings mutant in Bombyx mori is associated with a lack of scale precursor cell differentiation followed by excessive apoptosis. Dev Genes Evol 2006, 216:721-726.

48. Kaneko Y, Takaki K, Iwami M, Sakurai S: Developmental Profile of Annexin IX and its Possible Role in Programmed Cell Death of the Bombxy mori Anterior silk Gland. Zoological Science 2006, 23:533-542.

49. Tambunan J, Chang PK, Li H, Natori M: Molecular cloning of a cDNA encoding a silkworm protein that contains the conserved $\mathrm{BH}$ regions of Bcl-2 family proteins. Gene 1998, 212:287-293.

50. Huang Q, Deveraux QL, Maeda S, Stennicke HR, Hammock BD, Reed JC: Cloning and characterization of an inhibitor of apoptosis protein (IAP) from Bombyx mori. Biochimica et Biophysica Acta 2001, 1499:191-198.

51. Pei Z, Reske G, Huang Q, Hammock BD, Qi Y, Chejanovsky N: Characterization of the Apoptosis Suppressor Protein P49 from the Spodoptera littoralis Nucleopolyhedrovirus. The Journal Biological Chemistry 2002, 277(50):48677-48684.

52. Duan J, Zhu H, Zha X, Zhao P, Xia Q: Cloning and Sequence Analysis of the Caspase Gene, Bmlce, Related to the Apoptosis in the Silkworm. Science of Sericulture 2005, 31(3):261-267.

53. Song $L N$, Wang WB, Li B, Shen WD: Cloning of interlukin-1 $\beta$-converting enzyme (ICE) apoptosis-related genes from Bombyx mori and its expression in Escherichia coli. Journal of AnhuiAgriculturalUniversity 2007, 34(2):270-273.

54. Bryant B, Zhang Y, Zhang C, Santos CP, Clem RJ, Zhou L: A lepidopteran orthologue of reaper reveals functional conservation and evolution of IAP antagonists. Insect Molecular Biology 2009, 18(3):341-351.

55. Uno T, Nakao A, Fujiwara Y, Katsurauma C, Nakada T, Itoh O: Molecular Cloning and Expression of Protein Kinase C From Bombyx mori. Archives of Insect Biochemistry and Physiology 2006, 61:65-76.

56. Wang ZX, Wang P, Yao L, Zeng ZD, Xu HF, Duan J, Wang GH, Xia QY: Molecular Cloning, Sequence and Function Analyses and Specific Expression of Gene BmICAD Related to Apoptosis in Silkworm, Bombyx mori. Hereditas(Beijing) 2006, 28(7):838-844.

57. Iwasaki H, Takahashi M, Niimi T, Yamashita O, Yaginuma T: Cloning of cDNAs encoding Bombyx homologues of Cdc2 and Cdc2-related kinase from eggs. Insect Molecular Biology 1997, 6(2):131-141.

58. Xia Q, Zhou Z, Lu C: A Draft Sequence for the Genome of the Domesticated Silkworm (Bombyx mori). Science 2004, 306:1937-1940.

59. Xia Q, Cheng D, Duan J: Microarray-based gene expression profiles in multiple tissues of the domesticated silkworm, Bombyx mori. Genome Biology 2007, 8(8):R162.

60. Fujiwaraa Y, Shindomeb C, Takedab M, Shiomi K: The roles of ERK and P38 MAPK signaling cascades on embryonic diapause initiation and termination of the silkworm, Bombyx mori. Insect Biochemistry and Molecular Biology 2006, 36:47-53.

61. Katsuma S, Mita K, Shimada T: ERK- and JNK-Dependent Signaling Pathways Contribute to Bombyx mori Nucleopolyhedrovirus Infection. Journal of Virology 2007, 81(24):13700-13709.

62. Wang $Y$, Gu X: Functional Divergence in the Caspase Gene Family and Altered Functional Constraints: Statistical Analysis and Prediction. Genetics 2001, 158:1311-1320.

63. Chen P, Rodriguez A, Erskine Robert, Thach T, Abrams JM: Dredd, a Novel Effector of the Apoptosis Activators Reaper, Grim, and Hid in Drosophila. Developmental Biology 1998, 201:202-216.

64. Coopera DM, Piob F, Thia EP, Theilmannc D, Lowenberger C, Characterization of Aedes Dredd: A novel initiator caspase from the yellow fever mosquito, Aedes aegypti. Insect Biochemistry and Molecular Biology 2007, 37:559-569.

65. Lowenberger DMCDJGC: The insect caspases. Apoptosis 2009, 14:247-256.

66. Vernooy SY, Chow V, Su J, Verbrugghe K, Yang J, Cole S, Olson MR, Hay aBA: Drosophila Bruce Can Potently Suppress Rpr- and GrimDependent but Not Hid-Dependent Cell Death. Current Biology 2002, 12:1164-1168.

67. Wang CX, Youle RJ: The Role of Mitochondria in Apoptosis. Annu Rev Genet 2009, 43:95-118.

68. Silke J, Verhagen A, Ekert P, Vaux D: Sequence as well as functional similarity for DIABLO/Smac and Grim, Reaper and Hid? Cell Death and Differentiation 2000, 7:1275 
69. Steller H: Regulation of apoptosis in Drosophila. Cell Death and Differentiation 2008, 15:1132-1138.

70. Ware CF: The TNF Superfamily. Cytokine \& Growth Factor Reviews 2003, 14:181-184.

71. Bryant B, Blair CD, Olson KE, Clem RJ: Annotation and expression profiling of apoptosis-related genes in the yellow fever mosquito, Aedes aegypti. Insect Biochem Mol Biol 2008, 38(3):331-345.

72. Bryant B, Ungerer MC, Liu Q, Waterhouse RM, Clem RJ: A caspase-like decoy molecule enhances the activity of a paralogous caspase in the yellow fever mosquito, Aedes aegypti. Insect Biochemistry and Molecular Biology 2010, 40:516-523.

73. Wyatt SS: Culture in vitro of tissue from the silkworm, Bombyx mori L. J Gen Physiol 1956, 39(6):841-852.

74. Pan MH, Xiao SQ, Chen M, Hong XJ, Lu C: Establishment and characterization of two embryonic cell lines of Bombyx mori In Vitro. Cell Dev Biol-Animal 2007, 43:101-104.

75. Tamura K, Dudley J, Nei M, Kumar S: MEGA4: Molecular Evolutionary Genetics Analysis (MEGA) Software Version 4.0. Mol Biol Evol 2007, 24(8):1596-1599.

76. The new TNF nomenclature scheme. [http://www.genenames.org/ genefamily/tnfsf.php].

77. Dempsey PW, Doyle SE, He JQ, Cheng G: The signaling adaptors and pathways activated by TNF superfamily. Cytokine \& Growth Factor Reviews 2003, 14:193-209.

78. Gruss H, Dower S: Tumor necrosis factor ligand superfamily: involvement in the pathology of malignant lymphomas. bloodjournal 1995, 85:3378-3404

79. Eckhart L, Ballaun C, Uthman A, Kittel C, Stichenwirth M, Buchberger M, Fischer H, Sipos W, Tschachler E: Identification and Characterization of a Novel Mammalian Caspase with Proapoptotic Activity. Journal of Biological Chemistry 2005, 280(42):35077-35080.

80. Robertson AJ, Croce J, Carbonneau S, Voronina E, Miranda E, McClay DR, Coffman JA: The genomic underpinnings of apoptosis in Strongylocentrotus purpuratus. Developmental Biology 2006, 300:321-334.

81. Santos NMSd, Vale Ad, Reis MIR, Silva MT: Fish and Apoptosis: Molecules and Pathways. Current Pharmaceutical Design 2008, 14:148-169.

doi:10.1186/1471-2164-11-611

Cite this article as: Zhang et al:: The genomic underpinnings of apoptosis in the silkworm, Bombyx mori. BMC Genomics 2010 11:611.

\section{Submit your next manuscript to BioMed Central and take full advantage of:}

- Convenient online submission

- Thorough peer review

- No space constraints or color figure charges

- Immediate publication on acceptance

- Inclusion in PubMed, CAS, Scopus and Google Scholar

- Research which is freely available for redistribution

Submit your manuscript at www.biomedcentral.com/submit
Biomed Central 